\title{
Review of: "Analysis of the spatio-temporal network of air pollution in the Yangtze River Delta urban agglomeration, China"
}

\author{
Ehsan Elahi
}

Potential competing interests: The author(s) declared that no potential competing interests exist.

The article entitled "Analysis of the spatio-temporal network of air pollution in the Yangtze River Delta urban agglomeration, China? is interesting to read and according to scope of the journal. The article is publishable in the journal after addressing major revision.

Main concerns are:

1. It is better that you can start abstract directly from the main objectives of the article.

2. In the first line of introduction, it is stated that "With the rapid development of industrialization and urbanization, China's economy has achieved rapid growth, but the country has suffered serious air pollution" but what will be the impact of air pollution. Authors must have to write about related studies. Or it can simply be modifying as "With the rapid development of industrialization and urbanization, China's economy has achieved rapid growth, but the country has suffered serious air pollution. Burning of fossil fuel caused the air pollution [1-2] which has negative impact on human health [3-4]".

[1] Understanding farmers' intention and willingness to install renewable energy technology: A solution to reduce the environmental emissions of agriculture. Volume 309, 1 March 2022, 118459.

https://doi.org/10.1016/j.apenergy.2021.118459. Applied Energy

[2] Application of an artificial neural network to optimise energy inputs: An energy-and cost-saving strategy for commercial poultry farms. Energy:123169. https://doi.org/10.1016/j.energy.2022.123169 [3] Air pollution risks human mental health: An implication of two-stages least squares estimation of interaction effects. Environmental Science and Pollution Research. https://doi.org/10.1007/s11356-01906612-x

[4] Effect of Air Pollution on Female Labor Supply: An Empirical Analysis Based on Data of Labor Force Dynamic Survey of China. Social Work in Public Health. Volume 35, 2020 - Issue 4.

2. It is recommended to update the statement with given reference "As one of the most developed regions in China, the Yangtze River Delta urban agglomeration (YRDUA) has suffered significant air issues [4, 5], and it has been listed as a key area for air pollution control in China [5-6]

[5] Study on the spatial differentiation of environmental governance performance of Yangtze river urban agglomeration in Jiangsu province of China. Land Use Policy. doi.org/10.1016/j.landusepol.2020.105063/ [6] Evolution and Driving Mechanism of Ecological Security: A Case Study of Yangtze River Urban Agglomeration. Integrated Environmental Assessment and Management (IEAM). 
3. "This policy alleviate the conflict of motivations for air pollution control and enhance the awareness of cooperation between cities, which provides an excellent opportunity for the coordinated governance of air pollution in the YRD [7]"

[7] The Cultivation Mechanism of Green Technology Innovation in Manufacturing Industry: From the Perspective of Ecological Niche. 2019. Journal of Cleaner Production, Volume 252, 10 April 2020, 119711. JCLP_119711.

4. It is recommended to add structure of article at the end of introduction.

5. The information of data source should have to provide in subsection 2.1.

6. The limitations of the study must have to embed in the section of conclusion. Therefore, there is no need to make a separate subsection for the study limitations. 